AJS Review 39:2 (November 2015), 489

(C) Association for Jewish Studies 2015

doi:10.1017/S0364009415000331

ABSTRACT OF HEBREW ARTICLE

\title{
ISRAEL AND THE NATiOnS IN JUDAh HALEVI'S \\ THOUGHT \\ Yishai Glasner
}

An integral part of Halevi's worldview is the existence of an ontological difference between Jews and gentiles. Conversion to Judaism cannot alter the fundamental nature of a non-Jew. It can only oblige a convert to adhere to the Torah law; his nationality remains unchanged. This disparity is a qualitative one. The fundamental fulfillment of the gentile is to be found in the intellect, unlike the fundamental fulfillment of the Jew that is to be found within the divine sphere. It is not Halevi's contention that a gentile cannot have a relationship with his creatorGod can be found in the intellectual plane, He may be discerned in the natural world. The fundamental difference between Jews and gentiles is that unlike the gentile, whose connection with the Almighty is an indirect intellectual one, the Jew has a conduit to the divine that enables a direct and supernatural connection with God. The intellect is therefore intrinsic to the gentile's relationship with God. However, given the limitations of the human intellect, gentiles cannot experience that relationship to the fullest. In order to attain this goal they must subjugate themselves to Jews, which enables the Jews to mediate between gentiles and God.

\author{
Yishai Glasner \\ Hebrew University \\ Jerusalem, Israel
}

